\title{
Evaluation of the Efficacy of Single Dose of Intravitreal Bevacizumab in the Management of Macular Edema due to Retinal Vein Occlusions
}

\author{
Vinit Shah ${ }^{1 *}$, Panneer Selvam V ${ }^{2}$, Sindhanai VP' ${ }^{1}$, Shobita Nair ${ }^{2}$, Amal \\ Gupta $^{2}$ and Radha Jayaraman ${ }^{2}$ \\ ${ }^{1}$ Retina and Vitreous Services, Arasan Eye Hospital, Erode, Tamil Nadu, India \\ ${ }^{2}$ Cataract Services, Arasan Eye Hospital, Erode, Tamil Nadu, India \\ *Corresponding Author: Vinit Shah, Retina and Vitreous Services, Arasan Eye \\ Hospital, Erode, Tamil Nadu, India.
}

Received: September 07, 2020

Published: September 23, 2020

(C) All rights are reserved by Vinit Shah., et al.

\footnotetext{
Abstract

Aim: Evaluation of the efficacy of single-dose intravitreal Bevacizumab in the management of macular edema due to retinal vein occlusions.

Objectives:

1. To evaluate the efficacy of single-dose intravitreal bevacizumab in the management of macular edema due to retinal vein occlusions in terms of reduction in central macular thickness.

2. To evaluate the efficacy single dose of intravitreal bevacizumab in the management of macular edema due to retinal vein occlusions in terms of improvement in visual acuity.
}

3. To evaluate the change in the Intraocular pressure in the eyes receiving intravitreal Bevacizumab.

Methods: This study was an Institutional Review Board approved prospective interventional study done in a Retina clinic at a tertiary eye hospital, where 45 patients were enrolled. All patients clinically diagnosed to have retinal vein occlusions with macular edema with all risk factors were enrolled for the study. After informed consent, all participants were subjected to the following examinations, visual acuity was recorded on Snellen's vision chart, followed by anterior segment evaluation, intraocular pressure, gonioscopy, slit-lamp biomicroscopy with 90D lens and fundus finding were confirmed by indirect ophthalmoscopy. Optical coherence tomography was done in every patient. The diagnosis of macular edema was established by clinical examination and optical coherence tomography was done to quantify central macular thickness (CMT) at baseline, 4 weeks and 8 weeks after a single injection of $1.25 \mathrm{mg}(0.05 \mathrm{ml})$ intravitreal Bevacizumab.

Results: The mean central macular thickness (CMT) at presentation was $482.88 \mu \mathrm{m} \pm 173.6 \mu \mathrm{m}$ (SD). The mean CMT decreased from baseline to $314.3 \mu \mathrm{m} \pm 129.9 \mu \mathrm{m}$ at one month. The mean CMT decreased to $237.1 \mu \mathrm{m} \pm 97.08 \mu \mathrm{m}$ at the end of 2 months which was statistically significant $(\mathrm{p}<0.05)$. The logarithm of minimal angle of resolution $(\operatorname{logMAR})$ vision at presentation $1.043 \pm 0.443$ improved to $0.690 \pm 0.424$ and $0.529 \pm 0.440$ at 1 month and 2 months respectively $(\mathrm{p}<0.05)$. There was no statistically insignificant change in IOP after a single injection of Bevacizumab.

Conclusion: Intravitreal Bevacizumab even in a single dose is effective in the treatment of all types of retinal vein occlusions. There was a statistically significant improvement in visual acuity, the decrease in the central macular thickness was also statistically significant and effects were maintained throughout the follow-up period without any changes in IOP.

Keywords: Retinal Vein Occlusions; Macular Edema; Intravitreal Bevacizumab; Optical Coherence Tomography; Center Macular Thickness; Visual Acuity; Intraocular Pressure

Citation: Vinit Shah., et al. "Evaluation of the Efficacy of Single Dose of Intravitreal Bevacizumab in the Management of Macular Edema due to Retinal Vein Occlusions". Acta Scientific Ophthalmology 3.10 (2020): 12-19. 


\section{Abbreviations}

CMT: Central Macular Thickness; OCT: Optical Coherence Tomography; logMAR: Logarithm of Minimal Angle of Resolution; SD: Standard Deviation; IOP: Intraocular Pressure; BCVA: Best Corrected Visual Acuity; BRVO: Branch Retinal Vein Occlusion; CRVO: Central Retinal Vein Occlusion

\section{Introduction}

In elderly patient Retinal vein occlusion is the second most common retinal vascular disease after diabetic retinopathy leading to vision loss. There are two different types, based on the site of occlusion. In branch retinal vein occlusion, the occlusion is typically at an arteriovenous intersection. In central retinal-vein occlusion, the block is at or proximal to the lamina cribrosa of the optic nerve, where the central retinal vein exits the eye [1].

The prevalence of Retinal vein occlusion in patients over 40 years of age is 1 - 2\% and affects 16 million persons worldwide $[2,3]$. Branch retinal-vein occlusion is four times as common as central retinal vein occlusion [4]. 10-year incidence of retinal-vein occlusion was found to be $1.6 \%$ in a population-based cohort study [5]. Bilateral retinal-vein occlusion is uncommon (occurring in about $5 \%$ of cases), although, in $10 \%$ of patients with retinal-vein occlusion in one eye, occlusion develops in the other eye over time [6]. Both branch retinal-vein occlusion and central retinal vein occlusion are further divided into the categories of perfused (nonischemic) and nonperfused (ischemic), each of which has implications for prognosis and treatment.

Vision loss from retinal vein occlusion is mainly due to macular ischemia, macular edema, or complications of the neovascular disease. Visual acuity depends on the extent of macular involvement from 6/6 to counting fingers [7]. Many patients with branch retinal vein occlusion have a good prognosis, with one study showing that half had a return to 20/40 vision or better within 6 months, without treatment [8].

Fluorescein angiography has been critical for differentiating between the ischemic and nonischemic type of vein occlusion and detecting macular edema by identifying the characteristic stellar pattern of cystoid macular edema. By correlating results from fluorescein angiography and optical coherence tomography (OCT), fluid accumulation within and under the sensory retina can be confirmed and localised [9].
Retinal ischemia causes increased production of vascular endothelial growth factor (VEGF), which causes vascular leakage and macular edema. High levels of VEGF also promote retinal hemorrhages and exacerbate capillary nonperfusion. Recently, intraocular injections of anti-VEGF such as Bevacizumab, ranibizumab, and pegaptanib have shown to reduce vascular leakage resulting in improvement in macular edema and accelerate resorption of retinal hemorrhages and prevent worsening of capillary nonperfusion. The ideal regimen has not been defined, but it appears that monthly injections early in the course control edema and may help to limit disease severity in a large percentage of patients [10].

Treatment modalities include grid pattern laser photocoagulation, intravitreal bevacizumab, and intravitreal triamcinolone acetonide injection. Laser treatment of cases with media opacity, such as retinal hemorrhage and cataract, is challenging, and laser treatment is only effective for non-ischemic type macular edema. However, intravitreal triamcinolone acetonide injections are also associated with complications such as the formation of cataracts and an increase in intraocular pressure [11]. Intravitreal bevacizumab appears to be an effective treatment for macular edema secondary to retinal vein occlusion. Eyes treated with intravitreal bevacizumab showed a significant reduction in central foveal thickness and improvement in visual acuity [12].

So, our study is to evaluate the efficacy of a single injection of intravitreal bevacizumab in the treatment of macular edema due to retinal vein occlusions using optical coherence tomography and visual acuity.

\section{Materials and Methods}

This was a Prospective, clinical interventional study. All patients attending Retina Clinic in a tertiary eye hospital, which are diagnosed cases of Retinal vein occlusion and fulfilled the inclusion criteria, were included. Clearance from the hospital ethical committee and the scientific committee was obtained to conduct the study. Before the patients were enrolled in the study, written informed consent was taken from all. Patients included for the study were a total of 45 eyes of 45 patients of clinically diagnosed cases of Retinal vein occlusion with macular edema confirmed with Optical coherence tomography (Stratus OCT ${ }^{\mathrm{TM}}$, Carl Zeiss Meditec Inc., USA).

Patients with any media opacities preventing adequate visualization of the fundus, patients with a history of macular edema due to diabetic retinopathy, vitreous hemorrhage, neovascular glauco- 
ma, optic atrophy, macular degeneration, and patients with a history of laser or intravitreal injection in the past in the affected eye were excluded from the study. In the case of uncontrolled systemic diseases like hypertension, diabetes mellitus, hyperlipidemia, systemic evaluation and treatment collaborated with general physician and fitness was obtained for the procedure for all patients.

At baseline, visual acuity was recorded on Snellen's vision chart and converted to log MAR (logarithm of the minimal angle of resolution) for statistical analysis, followed by anterior segment evaluation, intraocular pressure was recorded by Goldmann Applanation tonometry, gonioscopy was done using Sussman 4 mirror goniolens, Fundus finding was confirmed by, indirect ophthalmoscopy, and slit-lamp biomicroscopy with 90D lens. Optical coherence tomography was done in every patient. The diagnosis of macular edema was established by clinical examination and optical coherence tomography was done to quantify central macular thickness (CMT). These details were entered in a pre-structured proforma.

Written informed consent was taken from the patient after informing them about the documented adverse effects of the drug as well as the off label status of usage of drug. The patients enrolled for the study were administered a single dose of Intravitreal Bevacizumab $1.25 \mathrm{mg}(0.05 \mathrm{ml})$ under strict aseptic conditions in Operation theatre. Post injection patients were started on topical antibiotics.

After the injection, patients were followed up at regular intervals, on $3^{\text {rd }}$ day, 1 week, 1 month, and 2 months. At 1 month and 2 months after the initial injection, all the baseline investigations and tests were repeated and data was recorded. Data were entered in Excel and Data analysis was done with the help of SPSS 20.0 statistical software. A paired t-test was used to compare the mean CMT, BCVA and IOP values between time points before and after intravitreal Bevacizumab. We tested the statistical significance (at the confidence interval of 95\%) of differences for each of these parameters between the initial values and the values at various time points of 1 month and 2 months after injection.

\section{Results and Discussion}

In this study majority of the patients $(73.4 \%)$ were in the age group of 51-70 years, establishing the fact that retinal vein occlusion is more common in the $5^{\text {th }}$ and $6^{\text {th }}$ decade of life. The male to female ratio was found to be 1.14:1; there was no significant sexual predilection for retinal vein occlusion seen in our study. In our study right eye was affected in $60 \%$ and left eye in $40 \%$ of patients (Table 1).

\begin{tabular}{|l|c|c|}
\hline Age Group & Frequency & Percent \\
\hline 31 - 40 Years & 2 & 4.4 \\
\hline 41 - 50 Years & 6 & 13.3 \\
\hline 51 - 60 Years & 17 & 37.8 \\
\hline 61 - 70 Years & 16 & 35.6 \\
\hline 71 - 80 Years & 4 & 8.9 \\
\hline Sex & Frequency & Percent \\
\hline Male & 24 & 53.3 \\
\hline Female & 21 & 46.7 \\
\hline Laterality & Frequency & Percent \\
\hline Right & 27 & 60.0 \\
\hline Left & 18 & 40.0 \\
\hline Total & 45 & 100.0 \\
\hline
\end{tabular}

Table 1: Demographics data.

In our study, CRVO was found in $42.2 \%$ patients, BRVO in $48.9 \%$ patients, hemicentral retinal vein occlusion in $6.7 \%$ patients, and Tributary retinal vein occlusion (TRVO) in $2.2 \%$. In patients with BRVO, the majority of patients $59.1 \%$ (13 out of 22 ) had superotemporal quadrant BRVO, and 40.9\% (9 out of 22) had inferotemporal quadrant BRVO, none of the patients had nasal quadrant BRVO (Figure 1).

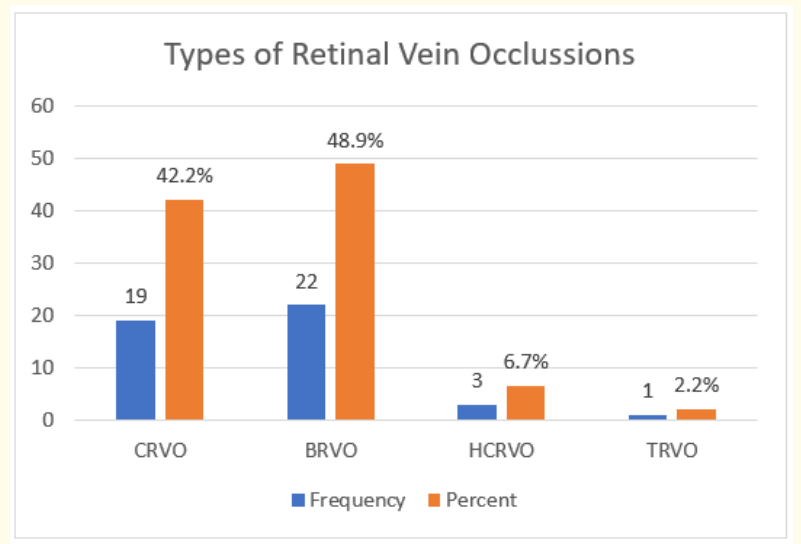

Figure 1: Types of retinal vein occlusion in the study. 
The mean central macular thickness (CMT) at presentation was $482.88 \mu \mathrm{m} \pm 173.6 \mu \mathrm{m}(\mathrm{SD})$. The mean CMT decreased from baseline to $314.3 \mu \mathrm{m}+129.9 \mu \mathrm{m}$ at 1 month. The mean CMT decreased to 237.1 $\mu \mathrm{m} \pm 97.08 \mu \mathrm{m}$ at the end of 2 months. The difference in the central macular thickness was statistically significant $(\mathrm{p}<0.05)$ at 1 month and 2 months from the baseline (Figure 2).

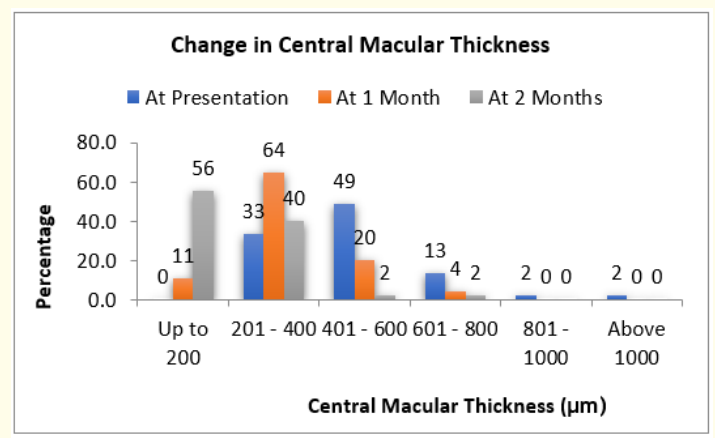

Figure 2: Distribution of central macular thickness after injection at subsequent visits.

The logarithm of minimal angle of resolution (logMAR) vision at presentation $1.043 \pm 0.443$ improved to $0.690 \pm 0.424$ and $0.529 \pm$ 0.440 at 1 month and 2 months respectively. The improvement in the visual acuity was found to be statistically significant $(\mathrm{p}<0.05)$ at 1 month and 2 months and was maintained (Table 2).
The intraocular pressure recorded by Goldmann applanation tonometry was $16.73 \mathrm{mmHg} \pm 2.623 \mathrm{mmHg}$ at baseline. The mean IOP at 1 month was $17.09 \mathrm{mmHg} \pm 2.592 \mathrm{mmHg}$. The mean IOP at $2 \mathrm{months}$ was $16.62 \mathrm{mmHg} \pm 2.534 \mathrm{mmHg}$. There was no statistically significant change in IOP noted (Figure 3 ).

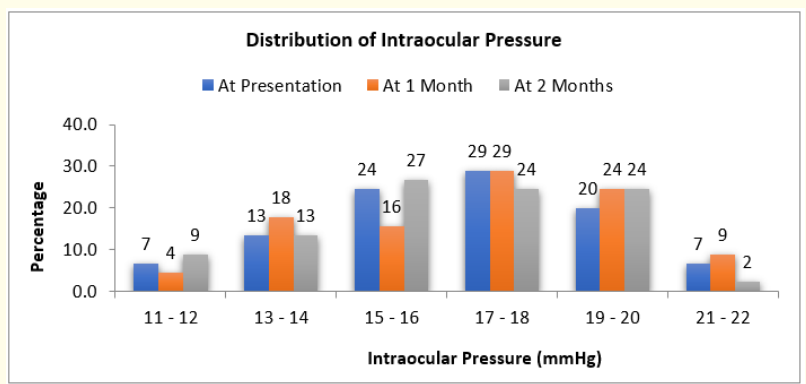

Figure 3: Comparison of the IOP at presentation, at 1 month and 2 months post injection.

No intraoperative complications were encountered. No other ocular complications such as retinal detachment, vitreous hemorrhage, or endophthalmitis were observed and no systemic complications such as myocardial infarction and cerebral infarction were observed during the course of the study.

\begin{tabular}{|l|c|c|c|c|c|c|}
\hline \multirow{2}{*}{$\begin{array}{l}\text { Visual } \\
\text { Acuity }\end{array}$} & \multicolumn{2}{|c|}{ At Presentation } & \multicolumn{2}{c|}{ At 1 Month } & \multicolumn{2}{c|}{ At 2 Months } \\
\cline { 2 - 7 } & Frequency & Percent & Frequency & Percent & Frequency & Percent \\
\hline $1 / 60$ & 6 & 13.3 & 2 & 4.4 & 1 & 2.2 \\
\hline $2 / 60$ & 6 & 13.3 & 1 & 2.2 & 1 & 2.2 \\
\hline $3 / 60$ & 2 & 4.4 & 1 & 2.2 & 1 & 2.2 \\
\hline $4 / 60$ & 0 & 0.0 & 1 & 2.2 & 2 & 4.4 \\
\hline $5 / 60$ & 7 & 15.6 & 3 & 6.7 & 1 & 2.2 \\
\hline $6 / 60$ & 9 & 20.0 & 6 & 13.3 & 4 & 8.9 \\
\hline $6 / 36$ & 4 & 8.9 & 6 & 13.3 & 5 & 11.1 \\
\hline $6 / 24$ & 3 & 6.7 & 7 & 15.6 & 3 & 6.7 \\
\hline $6 / 18$ & 6 & 13.3 & 7 & 15.6 & 5 & 11.1 \\
\hline $6 / 12$ & 1 & 2.2 & 4 & 8.9 & 6 & 13.3 \\
\hline $6 / 9$ & 1 & 2.2 & 5 & 11.1 & 11 & 24.4 \\
\hline $6 / 6$ & 0 & 0.0 & 2 & 4.4 & 5 & 11.1 \\
\hline Total & 45 & 100.0 & 45 & 100.0 & 45 & 100.0 \\
\hline
\end{tabular}

Table 2: Comparison of the best corrected visual acuity after injection at subsequent visits. 


\section{Discussion}

Laser photocoagulation applied in a grid distribution was shown to improve macular edema in the Branch and Central Vein Occlusion Study, but there was no improvement in visual acuity $[13,14]$. Other treatments such as laser-induced chorioretinal anastomosis, intravitreal tissue plasminogen activator and radial optic neurotomy have failed to show favorable results consistently. Intravitreal VEGF inhibitors are recently evaluated and many retrospective case series and prospective trials have shown positive effects of anti VEGFs in reducing macular edema and improving visual acuity in the patients with retinal vein occlusion. Our study shows the efficacy of a single injection of intravitreal bevacizumab in the treatment of retinal vein occlusion.

In our study, the mean age was 59.3 years with a range of 32 to 80 years. The majority of the patients $73.4 \%$ (33 out of 45 ) were in 51 - 70 years age group. RVO was found to be more prevalent in the $5^{\text {th }}$ and $6^{\text {th }}$ decade of life. Kazuyuki., et al. reported the mean age of the patients was $66.1 \pm 10.7$ years with a range from 34 years to 91 years in their study [15]. Costa., et al. in his study reported that the median age of the patients was 65 years (range, 58 - 74 years) [16]. Our study results were also similar to these studies.

There was no significant sexual predilection for the development of retinal vein occlusion seen in our study. Klein., et al. in the Beaver Dam Eye Study, found that the incidence of retinal vein occlusion was similar in men and women, our study results are also similar [3]. Ehlers., et al. in their study, bevacizumab for macular edema secondary to branch retinal vein occlusion, reported $53 \%$ of male patients and $47 \%$ of female patients, this was similar to our study [12].

The incidence of retinal vein occlusion was found to be more in the right eye in our study. Ehlers., et al. Bevacizumab for macular edema secondary to branch retinal vein occlusion, found that the right eye was involved in $59 \%$ of subjects and left eye in $41 \%$ of subjects [12]. Klein., et al. in their study, found that the incidence was similar in right and left eye, it did not match our study and the possible reason could be the small sample size in our study [3].

In patients with BRVO, the majority of patients 59.1\% (13 out of 22) had superotemporal quadrant BRVO and $40.9 \%$ (9 out of 22) had inferotemporal quadrant BRVO, none of the patients had nasal quadrant BRVO. Klein., et al. reported that of the eyes with retinal vein occlusion, the site of the branch vein occlusion involved the superotemporal quadrant in $58.1 \%$ of eyes (18/31), the inferotemporal quadrant in $29 \%$ of eyes $(9 / 31)$, and outside the temporal quadrants in $12.9 \%$ of eyes (4/31) [3]. Our study also showed simi- lar results with the superotemporal quadrant being the most common site.

There was a statistically significant decrease in the central macular thickness measured by OCT after injection of intravitreal Bevacizumab at 1 month and 2 months which was maintained over the follow-up period (Figure 4). Iturradle., et al. in his study, 16 eyes of 15 patients were treated, the mean central macular thickness was $887 \mu \mathrm{m}$ and decreased to $372 \mu \mathrm{m}$ at 1 month after injection. The mean follow-up was 3 months and the decrease in CMT was maintained in his study [17]. In a study by Figuerao., et al. in Spain, 18 eyes with CRVO, and 28 eyes with BRVO were treated. The mean central macular thickness decreased to $268.2 \mu \mathrm{m}$ (SD $62.5 \mu \mathrm{m}$ ) at 6 months from $486.9 \mu \mathrm{m}$ (SD $138.5 \mu \mathrm{m}$ ) at baseline in the BRVO group and to $326.17 \mu \mathrm{m}$ (SD $96.70 \mu \mathrm{m}$ ) in CRVO group [18]. Epstein., et al. in his prospective clinical trial of 30 patients with CRVO, received bevacizumab and 30 control patients received a sham injection, at the end of 6 months, the mean decrease in CMT was significantly greater, $426 \mu \mathrm{m}$ in the study group than in the control group (102 $\mu \mathrm{m})$. No residual edema was found in 26 of 30 patients $(86.7 \%)$ in the study group as compared with 6 of 30 patients $(20 \%)$ in the control group [19]. Our study showed similar results to these studies.

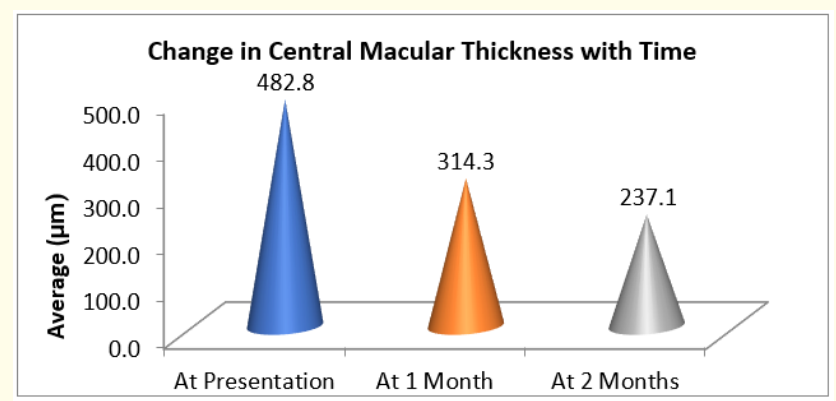

Figure 4: Comparision of reduction of central macular thickness ( $p<0.05$ statistically significant).

There was a significant change in the BCVA observed in the patients after the injection of bevacizumab and was maintained at the follow-up visit (Figure 5). Iturrdale., et al. in their study, treated 16 eyes of 15 patients. The mean baseline acuity was 20/600 (logMAR $=1.48$ ) and the mean acuity at month 1 was $20 / 200$ (logMAR = $1.05)$, a difference that was highly significant $(\mathrm{P}=0.001)$. At the last follow-up, a mean of 3 months after the first injection, the mean visual acuity was 20/138 (logMAR $=0.84)$, which was significantly better than baseline $(\mathrm{P}<0.001)$ [17]. Figuerao., et al. in their study found that in the BRVO group mean baseline logMAR visual acuity was 0.80 (SD 0.38) it improved to 0.44 (SD 0.34) at 6 months. In the 
CRVO group, the baseline logMAR values were 1.13 (SD 0.21) and it improved significantly to 0.83 (SD 0.45) at 6 months [18]. Epstein., et al. in their trial, had 30 patients with CRVO who received bevacizumab and 30 control patients who received a sham injection. At the end of 6 months, 18 of 30 patients $(60 \%)$ in the study group gained more than 15 letters compared with 6 of 30 patients in the control group $(\mathrm{P}=0.003)$ [19]. Our study results were comparable to these studies.

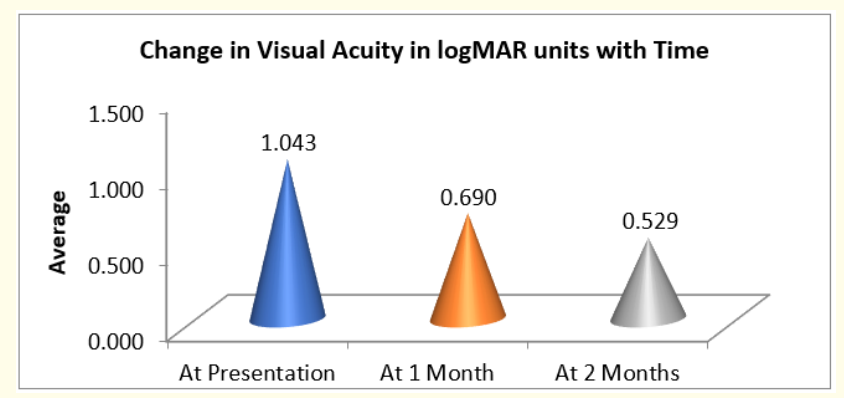

Figure 5: Change in visual acuity in logMAR units with time $(p<0.05$ statistically significant).

There was no significant change in IOP noted after the injection, the $p$-value at 1 month was $(p=0.207)$ and at 2 months $(p=$ 0.708 ), the $p$-value was greater than 0.05 which implies there was no statistically significant difference (Figure 6). Algevre PV., et al. intravitreal bevacizumab in CRVO, 18-months results of a prospective clinical trial, reported no increase in IOP at baseline it was 15.2
$\mathrm{mmHg}$ and $15.8 \mathrm{mmHg}$ at the end of their study [20]. Ali RI., et al. in their study found that the mean IOP was $21 \mathrm{mmHg}$ at 1 month and $15 \mathrm{mmHg}$ at the end of 3 months [21]. There was no raised IOP noted in the above studies and our results also match these studies.

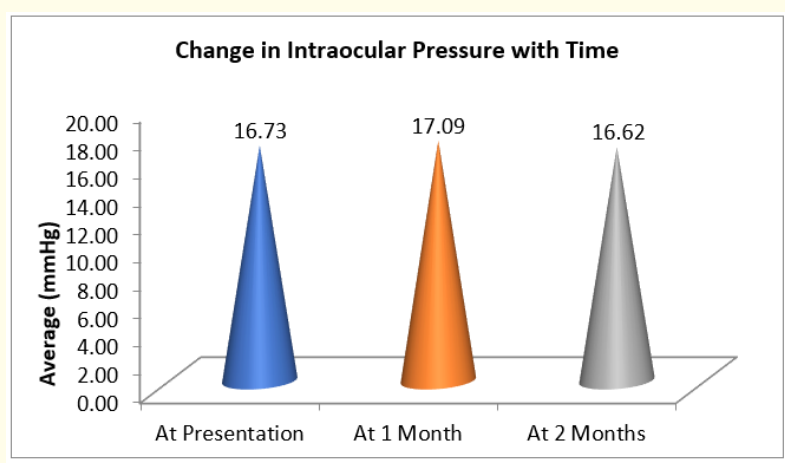

Figure 6: Change in intraocular pressure after injection ( $p>0.05$ statistically insignificant).

Pai, Sivakami A., et al. clinical, anatomic, and electrophysiologic evaluation following intravitreal bevacizumab for macular edema in retinal vein occlusion, concluded that no ocular toxicity or adverse effects were noted with the use of intravitreal bevacizumab in their study [22]. During our study period, we did not find any case of angle or iris neovascularization or adverse drug reaction. Our study showed similar results when compared with other published studies for treatment of macular edema due of Retinal vein occlusion with intravitreal bevacizumab (Table 3).

\begin{tabular}{|l|c|c|c|c|c|}
\hline Similar Studies & $\begin{array}{c}\text { Number of } \\
\text { patients }\end{array}$ & $\begin{array}{c}\text { Baseline } \\
\text { CMT }(\boldsymbol{\mu m})\end{array}$ & Baseline BCVA & $\begin{array}{c}\text { CMT at the end } \\
\text { of study }\end{array}$ & $\begin{array}{c}\text { BCVA at the end } \\
\text { of study }\end{array}$ \\
\hline Iturrdale., et al. [17] & 16 & 887 & $20 / 600$ & 372 & $20 / 138$ \\
\hline Figuerao., et al. [18] & 46 & 486 & logMAR 0.80 & 268 & $\operatorname{logMAR~} 0.44$ \\
\hline Kazuyuki., et al. [15] & 41 & 554 & logMAR 0.52 & 350 & $\operatorname{logMAR~} 0.31$ \\
\hline Jason HS., et al. [23] & 29 & 418 & $20 / 200$ & 285 & $20 / 80$ \\
\hline Rabena., et al. [24] & 27 & 478 & $20 / 200^{-}$ & 332 & $20 / 100$ \\
\hline This study & 45 & 482 & logMAR 1.043 & 237 & $\operatorname{logMAR~0.529}$ \\
\hline
\end{tabular}

Table 3: Comparisons of outcomes of other published studies with our study.

\section{Limitations of the Study}

The study did not take into consideration if the retinal vein occlusion was ischemic or nonischemic. FFA was not done for all the patients routinely. The study did not take into consideration the time from onset of symptoms and presentation to the hospital.
The patients requiring repeat injection after the completion of the study are not discussed here. Short follow up period, small sample size, and absence of a control group are limitations to conclusively demonstrate the advantages of the intravitreal bevacizumab. 


\section{Conclusion}

Intravitreous bevacizumab has the advantages of simplicity, relative safety, and is cost-effective when compared to the other treatments. Thus, we conclude that intravitreal bevacizumab even in a single dose is effective in the treatment of all types of retinal vein occlusions. The effects were maintained throughout the follow-up period and there was a statistically significant improvement in visual acuity and decrease in the central macular thickness.

\section{Acknowledgments}

I am extremely thankful to my mentor Dr. V. Panneer Selvam M.S, D.O., Medical Director, Arasan Eye Hospital for his wonderful support, encouragement, constructive criticism, and guidance at every step of this study. I extend my sincere thanks to Dr. S.G. Priya D.O. Consultant Ophthalmologist, Arasan Eye Hospital, Erode for her constant support throughout the study. It gives me great pleasure in acknowledging the valuable help and guidance that I received from Dr. Jeyanthan D.O., D.N.B. Special thanks to my colleagues Dr. Girish, Dr. Varalakshmi for their support. I am thankful to Mr. Jabir K.J, biostatistician for his valuable help in analyzing the data for this study.

\section{Conflict of Interest}

The study was funded by Arasan Eye Hospital Research Committee, Erode, Tami Nadu, India. The author(s) declare(s) that there is no conflict of interest.

\section{Bibliography}

1. Hayreh Sohan Singh. "Prevalent misconceptions about acute retinal vascular occlusive disorders". Progress in Retinal and Eye Research 24.4 (2005): 493-519.

2. Mitchell P., et al. "Prevalence and associations of retinal vein occlusion in Australia. The Blue Mountains Eye Study". Archives of Ophthalmology 114.10 (1996): 1243-1247.

3. Klein R., et al. "The epidemiology of retinal vein occlusion: the Beaver Dam Eye Study". Transactions of the American Ophthalmological Society 98 (2000): 133-141.

4. Rogers Sophie., et al. "The prevalence of retinal vein occlusion: pooled data from population studies from the United States, Europe, Asia, and Australia". Ophthalmology 117.2 (2010): 313-319.

5. Cugati Sudha., et al. "Ten-year incidence of retinal vein occlusion in an older population: the Blue Mountains Eye Study". Archives of Ophthalmology 124.5 (2006): 726-732.
6. McIntosh Rachel L., et al. "Natural history of central retinal vein occlusion: an evidence-based systematic review". Ophthalmology 117.6 (2010): 1113-1123.

7. Browning DJ. "Retinal vein occlusions Evidence-Based Management". New York. Springer-Verlag New York (2012).

8. Finkelstein D. "Ischemic macular edema. Recognition and favorable natural history in branch vein occlusion". Archives of Ophthalmology 110.10 (1992): 1427-1434.

9. Jonas Jost., et al. "Retinal vein occlusions". Developments in Ophthalmology 47 (2010): 111-135.

10. Nghiem-Buffet S Cohen SY., et al. "Retinal vein occlusions: anti VEGF treatments". JFA Ophthalmology 32.9 (2009): 679-686.

11. Cheng Kai-Chun and Wen-Chuan Wu. "Intravitreal triamcinolone acetonide for patients with macular edema due to branch retinal vein occlusion". The Kaohsiung Journal of Medical Sciences 22.7 (2006): 321-330.

12. Ehlers Justis P., et al. "Intravitreal bevacizumab for macular edema secondary to branch retinal vein occlusion". Retina 31.9 (2011): 1856-1862.

13. "Argon laser photocoagulation for macular edema in branch vein occlusion. The Branch Vein Occlusion Study Group". American Journal of Ophthalmology 98.3 (1984): 271-282.

14. "Evaluation of grid pattern photocoagulation for macular edema in central vein occlusion. The Central Vein Occlusion Study Group M report”. Ophthalmology 102.10 (1995): 1425-1433.

15. Kumagai Kazuyuki., et al. "Three treatments for macular edema because of branch retinal vein occlusion: intravitreous bevacizumab or tissue plasminogen activator, and vitrectomy". Retina 32.3 (2012): 520-529.

16. Costa Rogério A., et al. "Intravitreal bevacizumab (avastin) for central and hemicentral retinal vein occlusions: IBeVO study". Retina 27.2 (2007): 141-149.

17. Iturralde Diana., et al. "Intravitreal bevacizumab (Avastin) treatment of macular edema in central retinal vein occlusion: a short-term study". Retina 26.3 (2006): 279-284.

18. Figueroa M S., et al. "Results of bevacizumab as the primary treatment for retinal vein occlusions". The British Journal of Ophthalmology 94.8 (2010): 1052-1056. 
19. Epstein David LJ., et al. "Bevacizumab for macular edema in central retinal vein occlusion: a prospective, randomized, double-masked clinical study". Ophthalmology 119.6 (2012): 1184-1189.

20. Algvere Peep V., et al. "Intravitreal bevacizumab in central retinal vein occlusion: 18-month results of a prospective clinical trial”. European Journal of Ophthalmology 21.6 (2011): 789795.

21. Ali Rasha I., et al. "Efficacy of combined intravitreal bevacizumab and triamcinolone for branch retinal vein occlusion". Indian Journal of Ophthalmology 62.4 (2014): 396-399.

22. Pai Sivakami A., et al. "Clinical, anatomic, and electrophysiologic evaluation following intravitreal bevacizumab for macular edema in retinal vein occlusion". American Journal of Ophthalmology 143.4 (2007): 601-606.

23. Hsu Jason., et al. "Intravitreal bevacizumab (avastin) in central retinal vein occlusion". Retina 27.8 (2007): 1013-1019.

24. Rabena Melvin D., et al. "Intravitreal bevacizumab (Avastin) in the treatment of macular edema secondary to branch retinal vein occlusion". Retina 27.4 (2007): 419-425.

\section{Assets from publication with us}

- Prompt Acknowledgement after receiving the article

- Thorough Double blinded peer review

- Rapid Publication

- Issue of Publication Certificate

- High visibility of your Published work

Website: www.actascientific.com/

Submit Article: www.actascientific.com/submission.php

Email us: editor@actascientific.com

Contact us: +919182824667 